D) Check for updates

Cite this: Mater. Adv., 2021, 2, 3556

Received 29th March 2021 Accepted 6th May 2021

DOI: $10.1039 / \mathrm{d} 1 \mathrm{ma} 00278 \mathrm{c}$

rsc.li/materials-advances

\section{Poly(triethylene glycol methyl ether methacrylate) hydrogel as a carrier of phosphotungstic acid for acid catalytic reaction in water $\dagger$}

\author{
JunJie Zhu, ${ }^{a}$ Takehiko Gotoh, (D *a Satoshi Nakai, ${ }^{a}$ Nao Tsunoji ${ }^{\text {b }}{ }^{b}$ and \\ Masahiro Sadakane (iD *b
}

\begin{abstract}
A $\mathrm{H}_{3} \mathrm{PW}_{12} \mathrm{O}_{40}$-polymer composite was synthesized from a mixture of triethylene glycol methyl ether methacrylate monomer, triethylene glycol dimethacrylate crosslinker, and $\mathrm{H}_{3} \mathrm{PW}_{12} \mathrm{O}_{40}$. The heteropoly acid molecules were trapped in the hydrogel by hydrogen-bond interactions and did not leach out of the composite when washed with water. Therefore, this composite could be used as a heterogeneous catalyst for the hydrolysis of ethyl ester in water.
\end{abstract}

Despite their excellent yields and high selectivity, homogeneous catalysts have difficulties in catalyst separation, which limit their industrial applications. Thus, the construction of highly selective, active, stable, and easily recyclable heterogeneous catalysts remains a challenging goal in liquid-phase catalysis. ${ }^{1-4}$ Polyoxometalates (POMs) are discrete anionic metal oxide molecules formed by early transition metals at their highest oxidation states. ${ }^{5-7}$ This family of compounds has been studied extensively as their chemical properties can be greatly varied due to their structural characteristics, which make them suitable for applications in various fields like catalysis, energy, magnetism, and materials science. In the catalysis field, POMs are well known for their excellent acidity and nontoxicity. ${ }^{8,9}$ The Keggin-type $\left[\mathrm{XM}_{12} \mathrm{O}_{40}\right]^{\mathrm{n}-}(\mathrm{X}=\mathrm{P}, \mathrm{Si}, \mathrm{Ge}$, etc.; $\mathrm{M}=\mathrm{W}, \mathrm{Mo}$, etc.) structure is the most common and stable among the POM structures ${ }^{5,6}$ and is widely used for a variety of acid-catalyzed reactions. The Keggin-type phosphotungstic acid, $\mathrm{H}_{3} \mathrm{PW}_{12} \mathrm{O}_{40}$, has high acidity and thermal stability, and is widely used as a solid catalyst in the gas phase or as a homogeneous catalyst in the liquid phase. ${ }^{4,8-12}$ Unfortunately, $\mathrm{H}_{3} \mathrm{PW}_{12} \mathrm{O}_{40}$ readily dissolves in polar solvents, which limits its usefulness as a catalyst due to the associated separation cost.

\footnotetext{
${ }^{a}$ Department of Chemical Engineering, Graduate School of Advanced Science and Engineering, Hiroshima University, 1-4-1 Kagamiyama, Higashi-Hiroshima, 739-8527, Japan. E-mail: tgoto@hiroshima-u.ac.jp

${ }^{b}$ Department of Applied Chemistry, Graduate School of Advanced Science and Engineering, Hiroshima University, 1-4-1 Kagamiyama, Higashi-Hiroshima, 739-8527, Japan. E-mail: sadakane09@hiroshima-u.ac.jp

$\dagger$ Electronic supplementary information (ESI) available: Experimental details. See DOI: $10.1039 / \mathrm{d} 1 \mathrm{ma} 00278 \mathrm{c}$
}

Numerous studies have shown that heteropoly acids can be converted into heterogeneous catalysts when supported on materials such as silica, active carbon, and polymers with a high surface area. Most of these heterogeneous catalysts have shown better catalytic activity than heteropoly acids as homogeneous catalysts. ${ }^{13-15}$ However, the simple mixing of $\mathrm{H}_{3} \mathrm{PW}_{12} \mathrm{O}_{40}$ with support is not enough, because $\mathrm{H}_{3} \mathrm{PW}_{12} \mathrm{O}_{40}$ interacts weakly with the support material and can easily be leached from it when used in polar solvents. ${ }^{8}$ To enhance their interaction, materials have been designed using two main approaches: (1) electrostatic coupling between anionic POMs and an organic cation, and (2) covalent binding of POMs with organic linkers attached on the surface of the supports. ${ }^{13,14,16,17}$ To enhance the activity, high loading and high dispersion are also needed. The $\mathrm{H}_{3} \mathrm{PW}_{12} \mathrm{O}_{40}$-meso porous $\mathrm{SiO}_{2}$ composite is reported to maintain a $\mathrm{H}_{3} \mathrm{PW}_{12} \mathrm{O}_{40}$ loading of approximately $25 \mathrm{wt} \%$, but a continuous increase in loading results in a decrease in the specific surface area and the appearance of aggregated $\mathrm{H}_{3} \mathrm{PW}_{12} \mathrm{O}_{40}$ molecules. ${ }^{18-22}$ Here, we report a new material, a $\mathrm{H}_{3} \mathrm{PW}_{12} \mathrm{O}_{40} 0^{-}$ hydrogel composite, with a high loading amount (approx. $40 \mathrm{wt} \%$ ) that does not leach out when washed with water. We focused on the interaction between $\mathrm{H}_{3} \mathrm{PW}_{12} \mathrm{O}_{40}$ and an ether moiety, and used a hydrogel polymer containing an ethylene glycol moiety. $\mathrm{H}_{3} \mathrm{PW}_{12} \mathrm{O}_{40}$ is known to interact with ether even in water, ${ }^{5,23-26}$ and composites of di-vanadium-substituted phosphomolybdic acid and poly(ethylene glycol) are reported to show characteristic oxidation activity. ${ }^{27,28}$ Recently, it has been reported that $\mathrm{H}_{3} \mathrm{PW}_{12} \mathrm{O}_{40}$ and $\mathrm{H}_{4} \mathrm{SiW}_{12} \mathrm{O}_{40}$ have been homogeneously mixed with a loading as high as $70 \mathrm{wt} \%$, and $\mathrm{H}_{3} \mathrm{PW}_{12} \mathrm{O}_{40}$-PEG composites have shown high proton conductivity. ${ }^{29,30}$ The controlled assembly of heteropoly acid with a block-co-polymer containing poly(ethylene glycol) blocks has attracted much attention. ${ }^{31}$ The POM and polymer composite can be used in a variety of applications such as wearable strain sensors, ${ }^{32}$ luminescent materials, ${ }^{33,34}$ and antibacterial materials. ${ }^{35}$

Our design for a polymer containing a new heteropoly acid, $\mathrm{H}_{3} \mathrm{PW}_{12} \mathrm{O}_{40}$, for heterogeneous acid catalysis in water is as follows: (1) the polymer contains ethylene glycol ether to readily attach to $\mathrm{H}_{3} \mathrm{PW}_{12} \mathrm{O}_{40}$ and (2) the polymer is 3D-networked to limit its solubility in water. The $\mathrm{H}_{3} \mathrm{PW}_{12} \mathrm{O}_{40}$-polymer composite was 


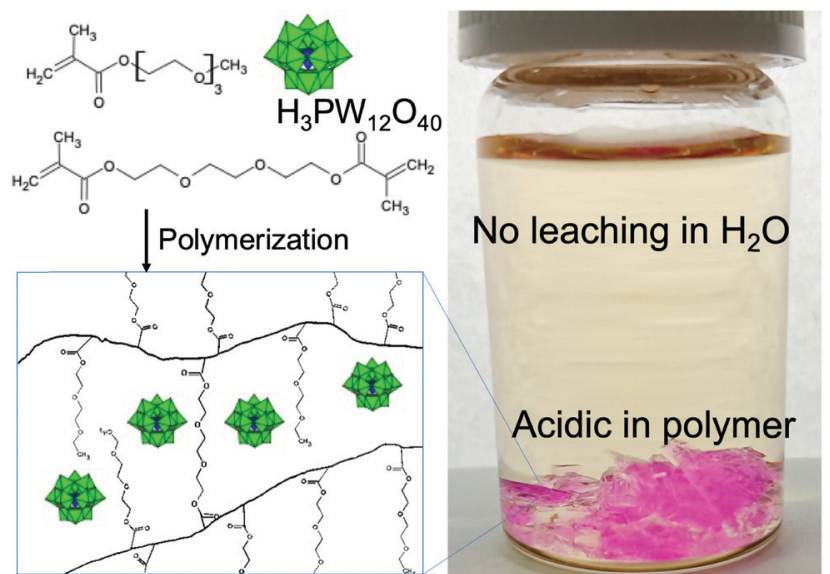

Scheme 1 Schematic of $\mathrm{H}_{3} \mathrm{PW}_{12} \mathrm{O}_{40}$ trapped in TEGMA gel (left) and photograph of the composite in TBS (right).

synthesized via a simple radical polymerization reaction using asobis(isobutyronitrile) (AIBN) in a mixture of triethylene glycol methyl ether methacrylate (TEGMA) monomer, triethylene glycol dimethacrylate (TEGDMA) crosslinker, and $\mathrm{H}_{3} \mathrm{PW}_{12} \mathrm{O}_{40}$ (Scheme 1). $\mathrm{H}_{4} \mathrm{SiW}_{12} \mathrm{O}_{40}$ has been reported to have been homogeneously mixed with an acrylate ester monomer, which was then polymerized by AIBN. ${ }^{36}$ The heteropoly acid molecules were trapped in the hydrogel by polymer chains by hydrogen-bond interaction forces. Thus, the heteropoly acid is prevented from being lost by leaching when washed with water (Scheme 1). The suitability of the $\mathrm{H}_{3} \mathrm{PW}_{12} \mathrm{O}_{40^{-}}$ poly-TEGMA composite as a catalyst was evaluated via leaching tests and catalytic experiments (see section S1, ESI $\dagger$ ).

At $298 \mathrm{~K}$, the $\mathrm{H}_{3} \mathrm{PW}_{12} \mathrm{O}_{40}$ solid can be fully dissolved in the TEGMA monomer at a high concentration (approx. $80 \mathrm{wt} \%$ ) to form a clear and stable solution. The color of the solution gradually turned light yellow with increase in the $\mathrm{H}_{3} \mathrm{PW}_{12} \mathrm{O}_{40}$ concentration (Fig. S1(a), ESI $\dagger$ ). Similarly, the dissolving of $\mathrm{H}_{4} \mathrm{SiW}_{12} \mathrm{O}_{40}$ in acrylate ester molecules has been reported. ${ }^{37}$ The refractive index of the clear solution also increased with the addition of $\mathrm{H}_{3} \mathrm{PW}_{12} \mathrm{O}_{40}$ (Fig. S2, ESI, $\dagger$ black balls). Finally, clear plate composites were produced by free-radical polymerization using AIBN as an initiator and the TEGMA monomer with TEGDMA as a crosslinker (Fig. S3, ESI $\dagger$ ).

Fig. S4 (ESI $\dagger$ ) shows the FT-IR spectra of the poly-TEGMA hydrogel, pure $\mathrm{H}_{3} \mathrm{PW}_{12} \mathrm{O}_{40}$, and $\mathrm{H}_{3} \mathrm{PW}_{12} \mathrm{O}_{40}$-poly-TEGMA composites. In the IR spectrum of pure $\mathrm{H}_{3} \mathrm{PW}_{12} \mathrm{O}_{40}$, the absorption bands at $1081 \mathrm{~cm}^{-1}, 978 \mathrm{~cm}^{-1}, 896 \mathrm{~cm}^{-1}$, and $802 \mathrm{~cm}^{-1}$ are characteristic of the absorptions of the $\mathrm{P}-\mathrm{O}_{\mathrm{a}}$ bond and the three $\mathrm{W}-\mathrm{O}$ bonds $\left(\mathrm{O}_{\mathrm{d}}\right.$, terminal oxygen to $\mathrm{W} ; \mathrm{O}_{\mathrm{b}}$, corner-sharing oxygen; and $\mathrm{O}_{\mathrm{c}}$, edge sharing oxygen), respectively (Fig. S5, ESI $\dagger$ ). ${ }^{29}$ The IR spectra of the 10-80 wt $\% \mathrm{H}_{3} \mathrm{PW}_{12} \mathrm{O}_{40}$-poly-TEGMA composite show the characteristic bands of $\mathrm{H}_{3} \mathrm{PW}_{12} \mathrm{O}_{40}$, which indicates the structural integrity of $\mathrm{H}_{3} \mathrm{PW}_{12} \mathrm{O}_{40}$ in the composites. The intensity of these bands strengthens with increase in the $\mathrm{H}_{3} \mathrm{PW}_{12} \mathrm{O}_{40}$ content. Interestingly, the absorption peak at $802 \mathrm{~cm}^{-1}$, which corresponds to the vibration of $\mathrm{W}-\mathrm{O}_{\mathrm{c}}$ in $\mathrm{H}_{3} \mathrm{PW}_{12} \mathrm{O}_{40}$, becomes sharper and shifts to $820 \mathrm{~cm}^{-1}$ (for $40 \mathrm{wt} \% \mathrm{H}_{3} \mathrm{PW}_{12} \mathrm{O}_{40}$-poly-TEGMA composite), which implies hydrogen-bond interactions between $\mathrm{H}_{3} \mathrm{PW}_{12} \mathrm{O}_{40}$ and TEGMA. A similar shape change and wavelength shift of the band at $802 \mathrm{~cm}^{-1}$ were observed when $\mathrm{H}_{3} \mathrm{PW}_{12} \mathrm{O}_{40}$ was mixed with poly(ethylene glycol). ${ }^{29}$ This suggests that the bridging oxo ligand, $\mathrm{O}_{c}$, has a comparatively higher negative charge and thus behaves as a hydrogen bonding acceptor group. The oxygens in $\mathrm{H}_{3} \mathrm{PW}_{12} \mathrm{O}_{40}$ can form hydrogen bonds with the ether groups of TEGMA, thereby contributing to the high solubility of $\mathrm{H}_{3} \mathrm{PW}_{12} \mathrm{O}_{40}$ in the TEGMA monomer. ${ }^{29,38}$

Fig. S6 (ESI $\dagger$ ) shows the XRD patterns of the poly-TEGMA hydrogel, pure $\mathrm{H}_{3} \mathrm{PW}_{12} \mathrm{O}_{40}$, and $\mathrm{H}_{3} \mathrm{PW}_{12} \mathrm{O}_{40}$-poly-TEGMA composites. Only broad diffraction peaks were observed in the $10-80 \mathrm{wt} \%$ $\mathrm{H}_{3} \mathrm{PW}_{12} \mathrm{O}_{40}$-poly-TEGMA composites, and no diffraction peak was assignable to the crystalline $\mathrm{H}_{3} \mathrm{PW}_{12} \mathrm{O}_{40}$ species, which indicates that the $\mathrm{H}_{3} \mathrm{PW}_{12} \mathrm{O}_{40}$-poly-TEGMA composites were amorphous. It can be inferred that the $\mathrm{H}_{3} \mathrm{PW}_{12} \mathrm{O}_{40}$ molecules were well dispersed in the poly-TEGMA carriers. Fig. 1 presents element mapping images of the $40 \mathrm{wt} \% \mathrm{H} 3 \mathrm{PW} 12 \mathrm{O} 40$-poly-TEGMA composite, which show that the distribution of elements $\mathrm{C}$ and $\mathrm{W}$ was highly consistent. These results further confirm that the $\mathrm{H}_{3} \mathrm{PW}_{12} \mathrm{O}_{40}$ molecules were finely dispersed in the poly-TEGMA hydrogel.

Fig. 2 shows the changes in the amount of $\mathrm{H}_{3} \mathrm{PW}_{12} \mathrm{O}_{40}$ in the $\mathrm{H}_{3} \mathrm{PW}_{12} \mathrm{O}_{40}$-poly-TEGMA composites with different $\mathrm{H}_{3} \mathrm{PW}_{12} \mathrm{O}_{40}$ loading amounts after they had been washed with water. Prior to washing, $\mathrm{H}_{3} \mathrm{PW}_{12} \mathrm{O}_{40}$ was successfully loaded into the poly-TEGMA hydrogel at all loading concentrations. When the loading concentration of $\mathrm{H}_{3} \mathrm{PW}_{12} \mathrm{O}_{40}$ was less than $40 \mathrm{wt} \%$, the loading amount of $\mathrm{H}_{3} \mathrm{PW}_{12} \mathrm{O}_{40}$ did not decrease after washing with water, which shows that $\mathrm{H}_{3} \mathrm{PW}_{12} \mathrm{O}_{40}$ can be fixed stably in poly-TEGMA hydrogel via the hydrogen bond interactions between $\mathrm{H}_{3} \mathrm{PW}_{12} \mathrm{O}_{40}$ and the polyTEGMA hydrogel. When the loading concentrations of $\mathrm{H}_{3} \mathrm{PW}_{12} \mathrm{O}_{40}$ were increased to $60 \mathrm{wt} \%$ and $80 \mathrm{wt} \%$, the loading concentrations of $\mathrm{H}_{3} \mathrm{PW}_{12} \mathrm{O}_{40}$ in the composite decreased to $51 \mathrm{wt} \%$ and $55 \mathrm{wt} \%$ after washing, respectively. This indicates that the loading capacity of poly-TEGMA hydrogel for $\mathrm{H}_{3} \mathrm{PW}_{12} \mathrm{O}_{40}$ had reached its limit, and the addition of $\mathrm{H}_{3} \mathrm{PW}_{12} \mathrm{O}_{40}$ in excess of this limit cannot be stably loaded. Fig. S7 (ESI $\dagger$ ) shows SEM images of the poly-TEGMA hydrogel, $40 \mathrm{wt} \% \mathrm{H}_{3} \mathrm{PW}_{12} \mathrm{O}_{40}$-poly-TEGMA composite, and $80 \mathrm{wt} \%$ $\mathrm{H}_{3} \mathrm{PW}_{12} \mathrm{O}_{40}$-poly-TEGMA composite. We can see that the polyTEGMA hydrogel and $40 \mathrm{wt} \% \mathrm{H}_{3} \mathrm{PW}_{12} \mathrm{O}_{40}$-poly-TEGMA composite have relatively flat surfaces and similar surface states. When the



Fig. 1 SEM patterns of the 40 wt $\% \mathrm{H}_{3} \mathrm{PW}_{12} \mathrm{O}_{40}$-poly-TEGMA composites (a), carbon (b), and tungsten (c). 


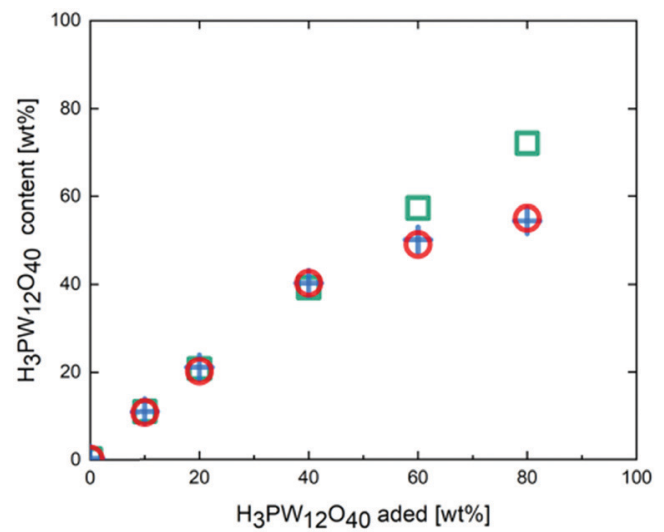

Fig. $2 \mathrm{H}_{3} \mathrm{PW}_{12} \mathrm{O}_{40}$ content estimated by thermogravimetry (TG) versus the amount of $\mathrm{H}_{3} \mathrm{PW}_{12} \mathrm{O}_{40}$ added in the polymerization. As-synthesized $\mathrm{H}_{3} \mathrm{PW}_{12} \mathrm{O}_{40}$-poly-TEGMA composites (green square), $\mathrm{H}_{3} \mathrm{PW}_{12} \mathrm{O}_{40}$-polyTEGMA composites after the first washing with water (blue cross), and $\mathrm{H}_{3} \mathrm{PW}_{12} \mathrm{O}_{40}$-poly-TEGMA composites after washing twice with water (red circle).

$\mathrm{H}_{3} \mathrm{PW}_{12} \mathrm{O}_{40}$ loading concentration exceeds $80 \mathrm{wt} \%$, many pocketshaped cavities can be observed on the surface. Combined with the results of the leaching test, this suggests that the change in the surface state of the composite is related to the $\mathrm{H}_{3} \mathrm{PW}_{12} \mathrm{O}_{40}$ loading concentration. We can conclude that when the loading concentration of $\mathrm{H}_{3} \mathrm{PW}_{12} \mathrm{O}_{40}$ in the poly-TEGMA hydrogel reaches its limit, the surface morphology of the composite will change.

Fig. S8(a) (ESI $\dagger$ ) shows the swelling behavior of composites with different $\mathrm{H}_{3} \mathrm{PW}_{12} \mathrm{O}_{40}$ loading amounts, and Fig. S8(b) (ESI $\dagger$ ) shows the calculated volume swelling rates. The volume of all the composites increases and the plate structure of the $80 \mathrm{wt} \%$ $\mathrm{H}_{3} \mathrm{PW}_{12} \mathrm{O}_{40}$ /TEGMA composite was broken (Fig. S8(a), ESI $\dagger$ ). The poly-TEGMA composites swelled even in the presence of $\mathrm{H}_{3} \mathrm{PW}_{12} \mathrm{O}_{40}$, with a volume swelling rate of about 3-4 (Fig. S8(b), ESI $\dagger$ ). This swelling behavior may facilitate the composite's absorption of the reactant from the solution and the completion of the catalytic reaction with the catalyst in the composite.

Fig. 3 shows the color change of the poly-TEGMA hydrogel and $\mathrm{H}_{3} \mathrm{PW}_{12} \mathrm{O}_{40}$-poly-TEGMA composites when immersed into thymol blue water solution. The thymol blue solution is yellow under neutral conditions and turns pink under acidic conditions with a pKa of 1.7. The poly-TEGMA hydrogel was yellow in the thymol blue solution (Fig. 3(b)), which means it had no acid sites. In comparison, the color of the $\mathrm{H}_{3} \mathrm{PW}_{12} \mathrm{O}_{40}$-poly-TEGMA

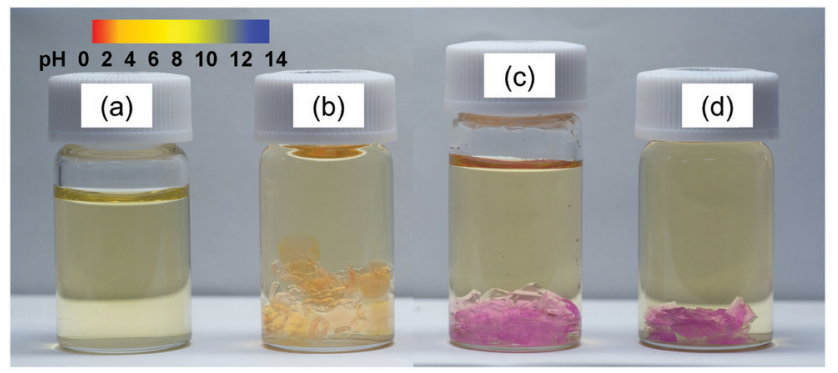

Fig. 3 Photograph of 0.0008 wt\% thymol blue water solution (TBS) (a), polyTEGMA hydrogel in the TBS (b), $20 \mathrm{wt} \% \mathrm{H}_{3} \mathrm{PW}_{12} \mathrm{O}_{40}$-poly-TEGMA composite in the TBS (c), 40 wt\% $\mathrm{H}_{3} \mathrm{PW}_{12} \mathrm{O}_{40}$-poly-TEGMA composite in the TBS (d). composite changed to pink, indicating the presence of acid sites in the $\mathrm{H}_{3} \mathrm{PW}_{12} \mathrm{O}_{40}$-poly-TEGMA composite. However, the color of the solution above the $\mathrm{H}_{3} \mathrm{PW}_{12} \mathrm{O}_{40}$-poly-TEGMA composite stayed the same as the thymol blue solution, which means that no protons of $\mathrm{H}_{3} \mathrm{PW}_{12} \mathrm{O}_{40}$ leached out from the composite, but remained locked stably in the composite.

As the hydrolysis of ethyl acetate can be catalyzed by acid, the activity and concentration of its acid sites are of great importance to its catalytic properties. Table S1 (ESI $\dagger$ ) shows the conversion of ethyl acetate after 72 hours with 0 wt $\%, 10$ wt $\%, 20 w t \%$ and $40 \mathrm{wt} \% \mathrm{H}_{3} \mathrm{PW}_{12} \mathrm{O}_{40}$-poly-TEMGA composites. It shows that higher $\mathrm{H}_{3} \mathrm{PW}_{12} \mathrm{O}_{40}$ contents lead to higher catalytic activity. Fig. 4(a) shows the conversion of ethyl acetate over time with the assynthesized and twice-washed $40 \mathrm{wt} \% \mathrm{H}_{3} \mathrm{PW}_{12} \mathrm{O}_{40}$-poly-TEMGA composites (solid lines), with the dotted lines indicating conversion after filtering. The results show that the synthesized and washed composites have similar curves, which means that the acid activity of the $40 \mathrm{wt} \% \mathrm{H}_{3} \mathrm{PW}_{12} \mathrm{O}_{40}$-poly-TEGMA composite did not decrease after washing with water. This also confirms that no $\mathrm{H}_{3} \mathrm{PW}_{12} \mathrm{O}_{40}$ leached out from the $40 \mathrm{wt} \% \mathrm{H}_{3} \mathrm{PW}_{12} \mathrm{O}_{40}$-poly-TEGMA composite. In addition, the conversion rate was almost the same
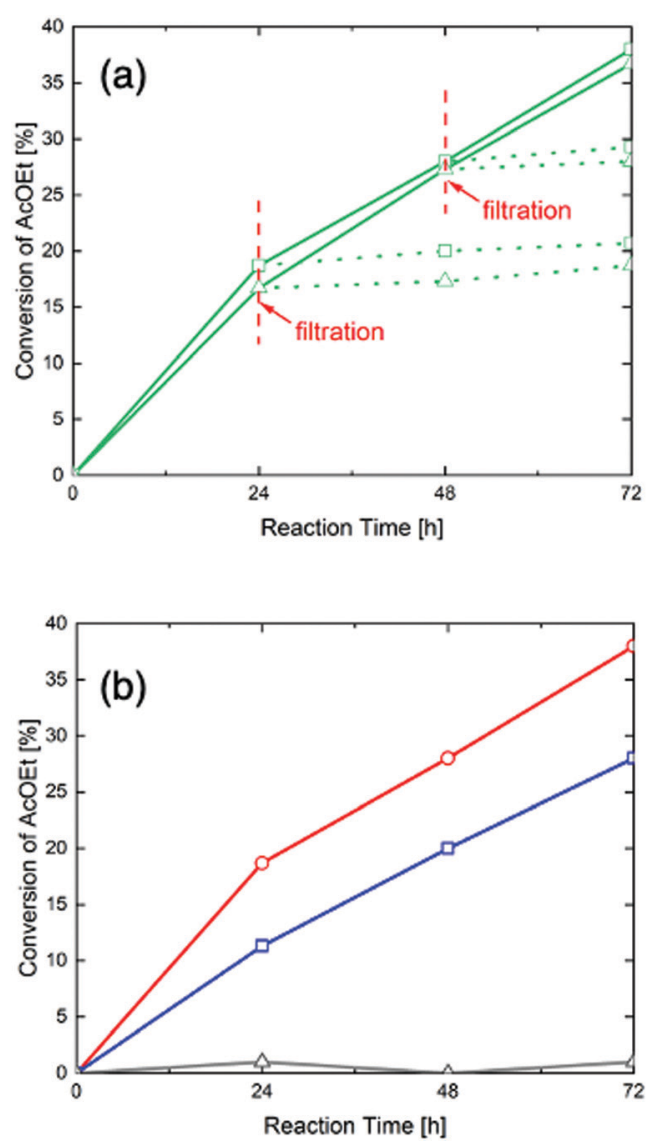

Fig. 4 Conversion change of AcOEt catalyzed by the as-synthesized $40 \mathrm{wt} \% \mathrm{H}_{3} \mathrm{PW}_{12} \mathrm{O}_{40}$-poly-TEGMA composite (square) and twice-washed $40 \mathrm{wt} \% \mathrm{H}_{3} \mathrm{PW}_{12} \mathrm{O}_{40}$-poly-TEGMA composite (triangle). Solid and dotted lines show the conversion change before and after filtering the composites, respectively (a); concentration changes of AcOEt catalyzed by polyTEGMA hydrogel (gray triangle), pure $\mathrm{H}_{3} \mathrm{PW}_{12} \mathrm{O}_{40}$ (blue square), and 40 wt\% $\mathrm{H}_{3} \mathrm{PW}_{12} \mathrm{O}_{40}$-poly-TEGMA composite (red circle) (b). 
after filtration, which indicates that no leaching of $\mathrm{H}_{3} \mathrm{PW}_{12} \mathrm{O}_{40}$ had occurred during the reaction. Fig. 4(b) shows the conversion changes of ethyl acetate with poly-TEGMA hydrogel, pure $\mathrm{H}_{3} \mathrm{PW}_{12} \mathrm{O}_{40}$, and $40 \mathrm{wt} \% \mathrm{H}_{3} \mathrm{PW}_{12} \mathrm{O}_{40}$-poly-TEGMA composite, where the pure $\mathrm{H}_{3} \mathrm{PW}_{12} \mathrm{O}_{40}$ and $40 \mathrm{wt} \% \mathrm{H}_{3} \mathrm{PW}_{12} \mathrm{O}_{40}$-poly-TEGMA composite had the same amount of $\mathrm{H}_{3} \mathrm{PW}_{12} \mathrm{O}_{40}$. The poly-TEGMA hydrogel shows no acid catalytic activity. The conversion of ethyl acetate with pure $\mathrm{H}_{3} \mathrm{PW}_{12} \mathrm{O}_{40}$ and 40 wt $\% \mathrm{H}_{3} \mathrm{PW}_{12} \mathrm{O}_{40}$-polyTEGMA composite both increased over time and the acid sites in the $\mathrm{H}_{3} \mathrm{PW}_{12} \mathrm{O}_{40}$-poly-TEGMA composite showed higher activities than the pure $\mathrm{H}_{3} \mathrm{PW}_{12} \mathrm{O}_{40}$. We can suppose that the high density of the composites supplied highly active acid sites for the hydrolysis of ethyl acetate, leading to a higher reaction speed.

In this work, we used poly-(triethylene glycol methyl ether methacrylate) (poly-TEGMA) to support phosphotungstic acid as an acid catalyst for the hydrolysis of ethyl acetate. During the synthesis process, $\mathrm{H}_{3} \mathrm{PW}_{12} \mathrm{O}_{40}$ was dissolved in the TEGMA monomer and the TEGDMA linker, and was polymerized using the AIBN initiator. The FT-IR, XRD, and SEM-EDX results suggest that the Keggin structure of the $\mathrm{H}_{3} \mathrm{PW}_{12} \mathrm{O}_{40}$ molecule is finely preserved in poly-TEGMA. The results of leaching and catalytic tests in water indicate that the $40 \mathrm{wt} \% \mathrm{H}_{3} \mathrm{PW}_{12} \mathrm{O}_{40^{-}}$ poly-TEGMA composite is stable, with $\mathrm{H}_{3} \mathrm{PW}_{12} \mathrm{O}_{40}$ not being leached when washed with water. The $40 \mathrm{wt} \% \mathrm{H}_{3} \mathrm{PW}_{12} \mathrm{O}_{40}$-polyTEGMA composite was proved to be a more efficient catalyst than pure $\mathrm{H}_{3} \mathrm{PW}_{12} \mathrm{O}_{40}$. This work provides new opportunities for extending the application range of heteropoly acids.

\section{Author contributions}

J. J. Zhu synthesized and analyzed the polymer composites and tested their catalytic activity. T. Gotoh, and S. Nakai synthesized and analyzed the polymer composites. N. Tsunoji tested their catalytic activity. M. Sadakane analyzed the polymer composites.

\section{Conflicts of interest}

There are no conflicts to declare.

\section{Acknowledgements}

This research was supported by JSPS KAKENHI, Grant Number JP18H02058 (Grant-in-aid for scientific research (B)); grant number JP 17K06892 (Grant-in-aid for scientific research (C)), Hosokawa Powder Technology Foundation, the Center for Polyoxometalate Science at Hiroshima University; and the JSPS core-to-core program.

\section{Notes and references}

1 F. Cavani, G. Centi, S. Perathoner and F. Trifirò, Sustainable Industrial Chemistry: Principles, Tools and Industrial Examples, John Wiley \& Sons, Ltd, 2009.

2 M. G. Clerici and O. A. Kholdeeva, Liquid Phase Oxidation via Heterogeneous Catalysis: Organic Synthesis and Industrial Applications, John Wiley \& Sons, Ltd, 2013.

3 D. Duprez and F. Cavani, Handbook of Advanced Methods and Processes in Oxidation Catalysis, Imperial College Press, 2014.
4 T. Okuhara, Chem. Rev., 2002, 102, 3641.

5 M. Tuboi, M. Hibino, N. Mizuno and S. Uchida, J. Solid State Chem., 2016, 234, 9.

6 C. L. Hill, Chem. Rev., 1998, 98, 1.

7 L. Cronin, Chem. Soc. Rev., 2012, 41, 7325.

8 F. Su and Y. Guo, Green Chem., 2014, 16, 2934.

9 M. Misono, Chem. Commun., 2001, 1141.

10 N. Mizuno and M. Misono, Chem. Rev., 1998, 98, 199.

11 I. Kozhevnikov, Chem. Rev., 1998, 98, 171.

12 S. Wang and G. Yang, Chem. Rev., 2015, 115, 4893.

13 V. Dufaud and F. Lefebvre, Materials, 2010, 3, 682.

14 F. Huang, Y. Su, Y. Tao, W. Sun and W. Wang, Fuel, 2018, 226, 417.

15 X. Liao, Y. Huang, Y. Zhou, H. Liu, Y. Cai, S. Lu and Y. Yao, Appl. Surf. Sci., 2019, 484, 917.

16 J. Yan, X. Zheng, J. Yao, P. Xu, Z. Miao, J. Li, Z. Lv, Q. Zhang and Y. Yan, J. Organomet. Chem., 2019, 884, 1.

17 W. Qi and L. Wu, Polym. Int., 2009, 58, 1217.

18 B. C. Gagea, Y. Lorgouilloux, Y. Altintas, P. A. Jacobs and J. A. Martens, J. Catal., 2009, 265, 99.

19 H. S. Yun, M. Kuwabara, H. S. Zhou and I. Honma, J. Mater. Sci., 2004, 39, 2341.

20 K. Nowińska, R. Formaniak, W. Kaleta and A. Wacław, Appl. Catal., A, 2003, 256, 115.

21 Y. Guo, K. Li, X. Yu and J. H. Clark, Appl. Catal., B, 2008, 81, 182. 22 H. Shen, Y. Li and S. Huang, Catal. Today, 2019, 330, 117.

23 T. Buchecker, X. Le Goff, B. Naskar, A. Pfitzner, O. Diat and P. Bauduin, Chem. - Eur. J., 2017, 23, 8434.

24 E. Drechel, Ber. Dtsch. Chem. Ges., 1887, 20, 1452.

25 B. Naskar, O. Diat, V. Nardello-Rataj and P. Bauduin, J. Phys. Chem. C, 2015, 119, 20985.

26 S. Yao, C. Falaise, A. A. Ivanov, N. Leclerc, M. Hohenschutz, M. Haouas, D. Landy, M. A. Shestopalov, P. Bauduin and E. Cadot, Inorg. Chem. Front., 2021, 8, 12.

27 A. Haimov and R. Neumann, Chem. Commun., 2002, 876.

28 R. Neumann and M. Lissel, J. Org. Chem., 1989, 54, 4607.

29 Z. Zheng, Q. Zhou, M. Li and P. Yin, Chem. Sci., 2019, 10, 7333.

30 T. Wen, L. Qiu, Z. Zheng, Y. Gong, J. Yuan, Y. Wang, M. Huang and P. Yin, Macromolecules, 2020, 53, 1415.

31 Y. Ren, Y. Zou, Y. Liu, X. Zhou, J. Ma, D. Zhao, G. Wei, Y. Ai, S. Xi and Y. Deng, Nat. Mater., 2020, 19, 203.

32 X. Wei, K. Ma, Y. Cheng, L. Sun, D. Chen, X. Zhao, H. Lu, B. Song, K. Yang and P. Jia, ACS Appl. Polym. Mater., 2020, 2, 2541.

33 L. Liang, N. Sun, Y. Yu, S. Ren, A. Wu and L. Zheng, Soft Matter, 2020, 16, 2311.

34 J. Yang, M. Chen, P. Li, F. Cheng, Y. Xu, Z. Li, Y. Wang and H. Li, Sens. Actuators, B, 2018, 273, 153.

35 Y. Fang, T. Liu, C. Xing, J. Chang and M. Li, Int. J. Pharm., 2020, 591, 119990.

36 T. Ishii, Y. Hoashi, S. Matsumoto, M. Kuroki, H. Jintoku, T. Ogata, Y. Kuwahara, M. Takafuji, S. Nagaoka and H. Ihara, Chem. Lett., 2017, 46, 489.

37 M. Sadakane, Y. Ichi, Y. Ide and T. Sano, Z. Anorg. Chem., 2011, 637, 2120.

38 M. J. Janik, R. J. Davis and M. Neurock, J. Am. Chem. Soc., 2005, 127, 5238. 